\title{
BIM-based Surface-specific Solar Simulation of Buildings
}

\author{
N. Salimzadeh ${ }^{\mathrm{a}}$, F. Vahdatikhaki ${ }^{\mathrm{b}}$, and A. Hammad \\ ${ }^{a}$ Ph.D. Student, Department of Building, Civil, and Environmental Engineering, Concordia University, Montreal, \\ Quebec, Canada \\ ${ }^{\mathrm{b}}$ Assistant Professor, Department of Construction Management and Engineering, University of Twente, The \\ Netherlands \\ ${ }^{c}$ Professor, Concordia Institute for Information Systems Engineering, Concordia University, Montreal, Quebec, \\ Canada.

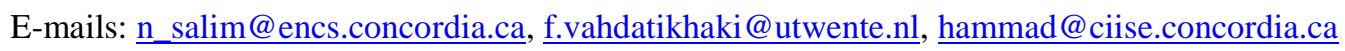

\begin{abstract}
-
Photovoltaic (PV) solar energy is rapidly growing as an attractive alternative to fossil fuels. PV panels can harvest the solar power and turn it into a clean source of electricity. Traditionally, PV panels are only used on the rooftops of buildings. However, with the emergence of building-integrated solar panels in recent years, other surfaces on the building façade can be considered for the installation of PV panels. Given that different panels have different cost and performance profiles, it is of a cardinal importance to properly design the PV panels on the building facades to ensure a maximum benefit-cost ratio.

Existing simulation and optimization methods do not discriminate between different types of surfaces of the building and treat the building envelope as a set of polygons. This can result in under- or over- design since there is a strong relationship between the type of the surfaces and the type of PV panels that can be attached to them or integrated with them. The advent of Building Information Modeling (BIM) in recent years has provided a rich platform for object-based evaluation and analysis of buildings. Nonetheless, currently, BIM is not used for a detailed and surfacespecific simulation of building surfaces.

In this research, a BIM-based method is developed for a detailed simulation of a building envelope using its surface properties. A prototype is developed using Dynamo visual programming platform to demonstrate the feasibility of the proposed method, and a case study is presented for a building in Montreal, Canada. In the light of the result of the case study, it can be concluded that the proposed method is promising in terms of providing the input for a comprehensive planning of the solar panel layout.
\end{abstract}

Keywords -

BIM; Solar Simulation; Building Façade

\section{Introduction}

The exacerbating global warming issues, on one hand, and the depleting fossil energy resources, on the other hand, are making the need for sustainable energy resources progressively palpable and vital. As one of the most promising options, photovoltaic (PV) solar energy is gaining growing popularity in recent years [1]. PV energy can be harvested using solar panels, and then transformed into a clean source of electricity that can be used in different industries. According to International Energy Agency (IEA) analysis, solar energy will provide $20-25 \%$ of the world electricity supply by 2050 [2].

Buildings account for up to $40 \%$ of the total energy use [3]. Therefore, the effective use of solar energy in buildings can tremendously contribute to the reduction of fossil energy. The increasing availability, affordability, and efficacy of PV panels are rendering them an attractive option for use in buildings. Traditionally, PV panels are only used on the rooftops of buildings. However, with the emergence of Building Integrated Photovoltaic (BIPV) in recent years, other surfaces of the building envelop can be considered for the installation of PV panels/films, as shown in Figure 1.

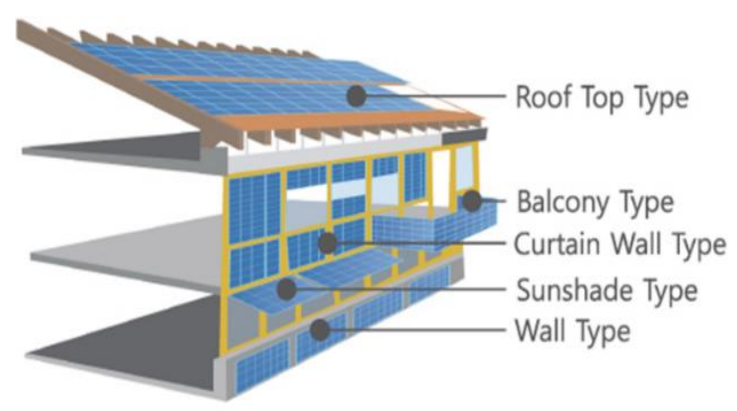

Figure 1. Different types of solar panels that can be used on building envelop 
For example, using PV panels on balcony fences, or applying semi-transparent modules for designing glass ceilings or facades can improve the aesthetical aspects [4]. Some PV products such as amorphous silicon tiles can replace the common tiles on roofs. Other PV materials can be applied as shading panels or semi-transparent fenestration films in the design process of new buildings or the renovation of existing buildings. Given that different panels/films have different cost and performance profiles, it is of a cardinal importance to properly design their installation on building surfaces to ensure a maximum benefit-cost ratio.

The ultimate goal of the building solar design is to determine the number, type, location, and orientation of the solar modules on the building exterior surfaces considering the lifecycle cost of the modules. Many researchers have addressed the problem of PV panel layout design and optimization in recent years [5 10]. Nevertheless, the prerequisite to a reliable layout design/optimization is an accurate solar radiation model for estimating the amount of the annual solar energy that each surface on the building envelop can potentially generate $[11,12]$. This model should capture the context of a building (i.e., location, orientation, geometry, surrounding buildings and vegetation, season, and weather conditions), to simulate the radiation potential. There are many different approaches for the simulation of the buildings' solar potential [13 17]. However, the majority of the available models work with either (1) 2D footprint of the buildings, or (2) approximated façades generated by the extrusion of $2 \mathrm{D}$ footprints. Both of these approaches are suitable for the design of PV panels for the horizontal surfaces (e.g., rooftops), and cannot be used for detailed analysis of vertical surfaces of the building. RADIANCE, Daysim, SORAM, SolarFlux, r.sun, ArcGIS Solar Analyst, and Sky View Factor are some examples of these radiation models [15].

The available methods are not suitable for a detailed planning of PV panels because the accurate 3D representation of the building envelop is not available; and thus, the radiation potential on the actual vertical surfaces cannot be calculated. In recent years, some researchers started to use 3D city models to consider the vertical facades [18, 19]. Nonetheless, while these methods can be used for the 3D simulation of the solar radiation, they are essentially geometric solutions that work with polygons and do not have the specific properties of the building objects. The disadvantage of these methods is that the distinction between different objects on the façade (e.g., balconies, curtain walls, windows, etc.) cannot be made easily. Accordingly, a detailed planning and optimization of PV modules where surface-specific characteristics are considered in a holistic way are not feasible.

On the other hand, the advent of Building Information
Modeling (BIM) in recent years has paved the way for the integrated management of building data throughout its lifecycle [20]. Since BIM provides easy access to information of various elements of the building, it can be best used for various types of simulations such as daylight, energy performance, and solar radiation simulations [21 24]. In a recent project, an open BIMbased platform is developed for designing and simulating energy efficient buildings to integrate the simulations in the virtual design office [25]. Also a research project in Germany is trying to integrate the energy active components into the building envelope based on the methodology of the Building Information Modelling [26] There are several software packages for solar analysis, such as ECOTECT [27] and Insight [28]. However, these packages transform the BIM 3D objects to a polygon mesh. During this process, the semantic information about different objects is lost. As a result, they treat the entire building envelope as a set of polygons with no distinction based on the object types. Consequently, the current tools are not geared toward the surface-specific solar analysis of the building, which is essential for a comprehensive design of PV solar modules.

Accordingly, the main objective of this paper is to develop a method for surface-specific solar simulation of buildings that can later be used for a comprehensive planning and design of PV modules. In this method, BIM and City Geographic Markup Language (CityGML) are integrated to capture both the object properties of a certain building and the surroundings of this building.

The remainder of this paper is structured as follows: first, the proposed method is explained in detail in Section 2. Then, the implementation and case study are presented in Section 3. Finally, the conclusions and future work are presented in Section 4.

\section{Proposed Method}

Figure 2 presents the overview of the proposed method. The main assumption of this method is that the BIM model of the target building and the CityGML model of the area are available.

This method focuses on the application of off-theshelf solar simulation software. As a result, the goal is not to develop a new BIM-based simulation tool that can use the object properties and attributes directly in the simulation. Instead, the focus is on creating classes of surfaces that associate with different types of building objects (e.g., exterior walls, roofs, curtain walls, windows, etc.) using BIM capabilities. These classes can be used to run the existing simulation tools on the different classes of surfaces, and thus enable surfacespecific simulation of the solar potential.

The BIM model can be available either at the design stage or use as-is modeling. Given that as-is BIM models 


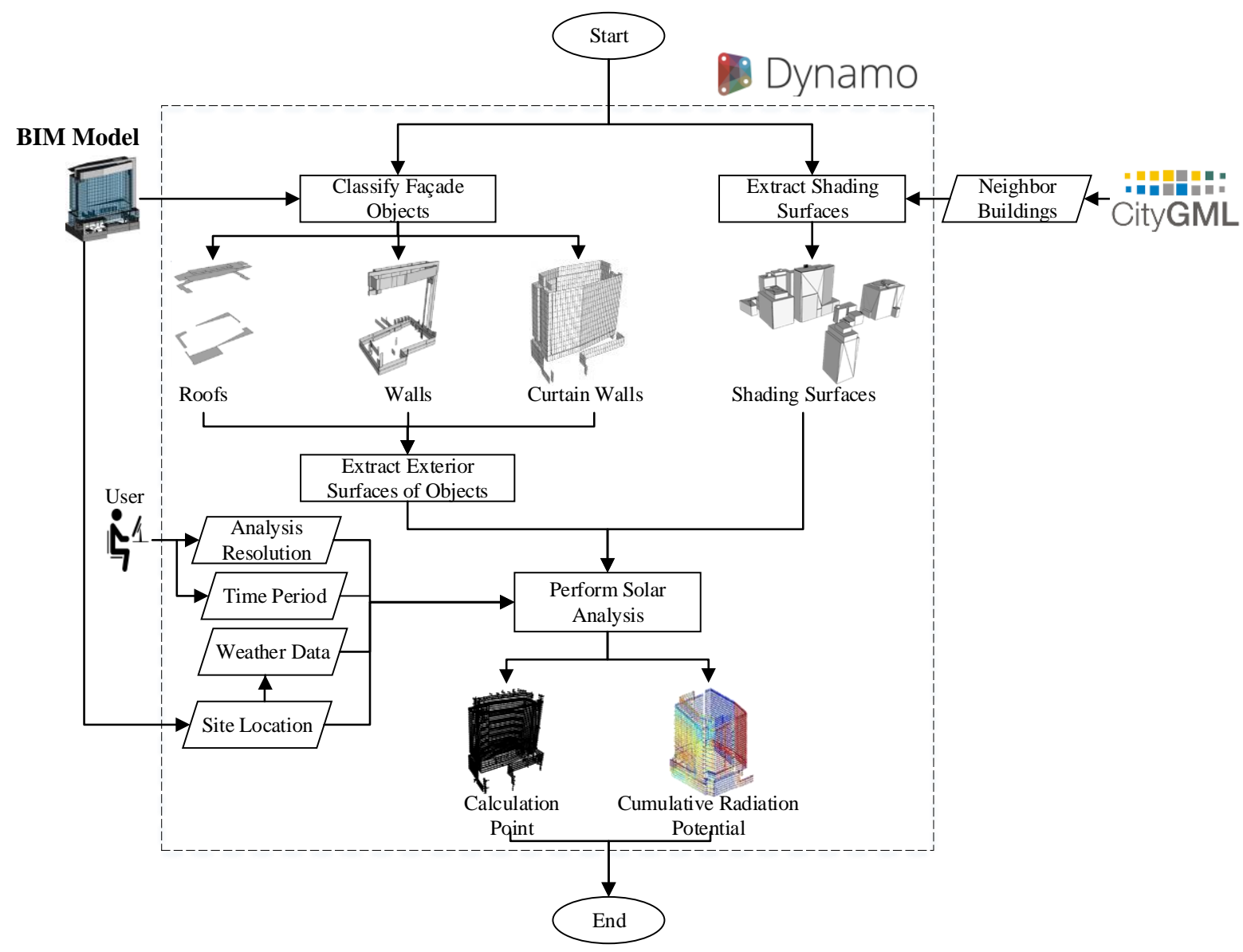

Figure 2. Overview of the proposed method

are not available for many of the existing buildings, as-is modeling is becoming popular in recent years using new technologies such as Light Detection and Ranging (LiDAR). Point cloud data captured by LiDAR can be converted into an object-based model manually or semiautomatically [29]. Although it is possible to scan the entire building (i.e., interior and exterior elements) with LiDAR and generate a complete as-is BIM model, it is sufficient to generate the $3 \mathrm{D}$ model of only the exterior of the building for the purpose of solar potential simulation and PV panel optimization. This can expedite the preparation of the BIM model required for the proposed method. Unmanned Ariel Vehicle (UAV)mounted LiDAR can be used to further facilitate this process [30].

For the purpose of PV panel planning and design, the Level of Detail (LoD) 200 would be sufficient. At this level of detail, the type and geometry (i.e., size, shape, location, and orientation) of building objects are known [31]. As per this criterion, the basic object detection and classification of the point clouds that can classify different object types (e.g., windows, curtain walls, etc.) and approximate their dimensions can be satisfactory. This allows the use of scan-to-BIM solutions, which reduce the amount of manual efforts required for the generation of BIM models [32, 33].

As shown in Figure 3, the BIM model provides the basis for the classification of different objects of the façade of the building. Depending on the types of the considered PV modules, the classification can be further expanded using the attributes of the elements.
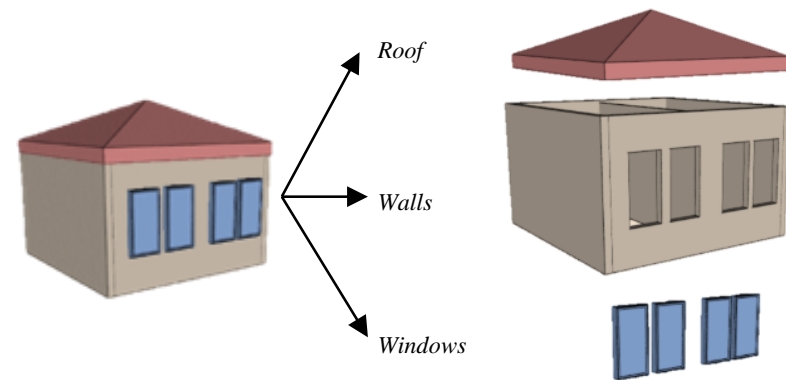

Figure 3. BIM-based classification of façade objects 
For instance, the length and width of windows can be used to classify the windows into sub-categories based on their sizes. Such detailed classification helps to select suitable PV modules for the objects based on the materials or sizes of the objects. However, the consideration of detailed attributes in the BIM model (e.g., materials) may necessitate higher LoDs of the BIM model.

After the classification, all the objects in each class are decomposed into the constituent surfaces. For each object, only the exterior surface is kept and the remaining surfaces are filtered out as they are irrelevant for the solar analysis, as shown in Figure 4.

On the other hand, CityGML can be used to capture the surrounding of the building. As shown in Figure 5(a) many cities are already using CityGML to provide highquality geo-referenced semantic models of their jurisdictions [34, 35]. Therefore, these models are becoming increasingly available for different areas.

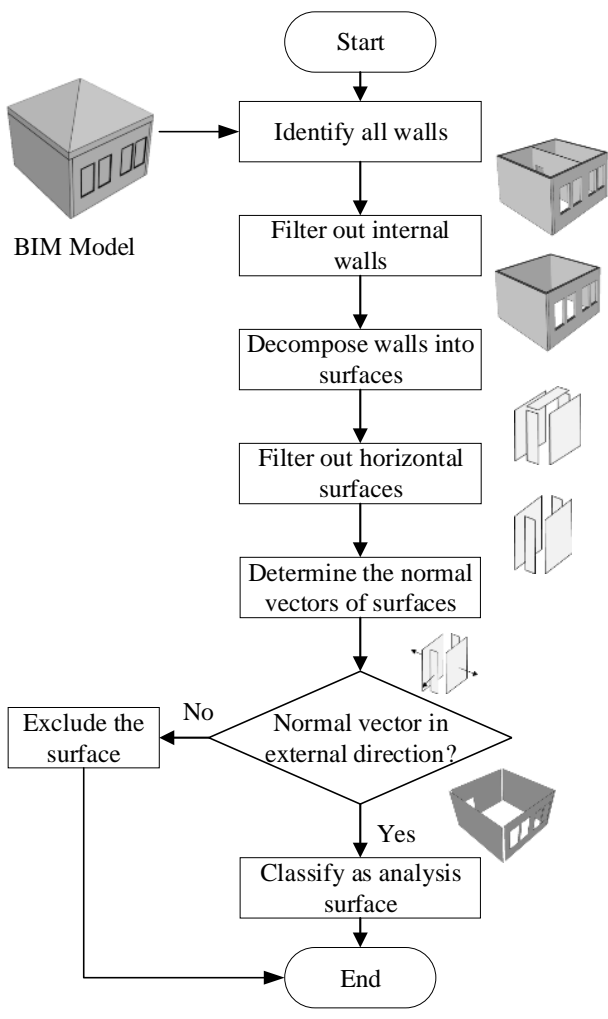

Figure 4. Flowchart for extraction of exterior surfaces from wall objects

The surrounding buildings are used to represent the objects that have shading effect on the study building. The CityGML model should be trimmed to include only buildings in the effective region of the building under consideration in order to reduce the computational effort of the simulation.

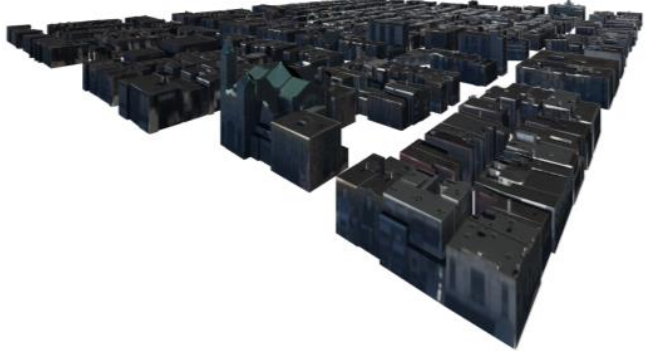

(a)

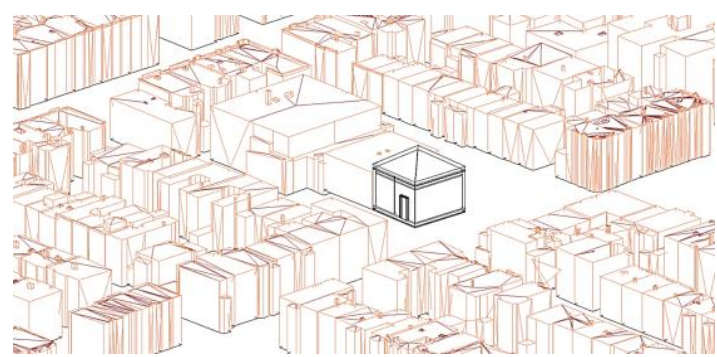

(b)

Figure 5. (a) An example of CityGML file of Montreal, (b) BIM and CityGML integration

The boundaries of the effective region are marked by the furthest buildings in different directions that can cast a shadow on the building under consideration. Whether or not a building has a shadow effect on the target building is a function of the height ratio of both buildings, the distance between the buildings, in-between obstacles, and their heights, and the orientation of buildings with respect to the true north. This calculation can be done in Geographic Information System (GIS) platforms, but it is outside the scope of the present research. Then, the CityGML model is merged with the BIM model of the building under consideration, as shown in Figure 5(b).

The next step after merging the surfaces of the buildings in one model is to run the solar simulation using off-the-shelf software (e.g., Autodesk Insight). In this step, a series of input from the user is required. Firstly, the resolution of the analysis should be specified, as shown in Figure 6(a). The resolution specifies how many calculation points on each study surface should be considered. The resolution should be selected based on the minimum size of the PV modules that are considered for the analysis and the available computational power.

The user needs to specify the time period of the simulation. While this period can be for any length and from any starting date, since the majority of PV panel optimization and design procedures are based on the annual solar potential, it is recommended to use a whole year for the time period. The site location can be obtained from the coordinates of the BIM model. Based on the 
location of the building, the weather data can be retrieved from national meteorological databases. Figure 6(b) presents an example of surface-specific simulation of solar potentials.
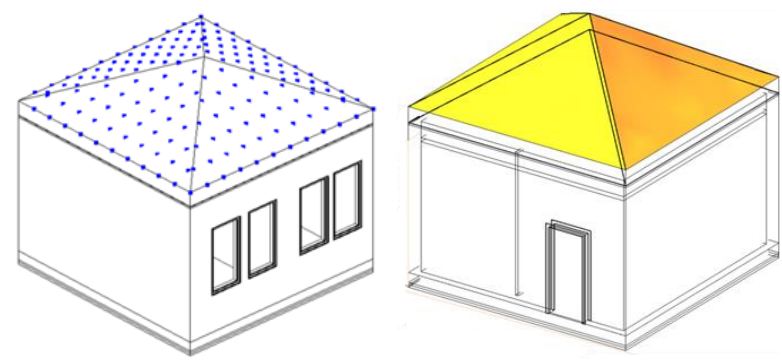

Figure 6. (a) Schematic representation of analysis resolution on the roof, (b) Surfacespecific simulation of solar potentials

\section{Implementation and Case Study}

The proposed method is developed in a prototype implementation. In this implementation, Revit [35] is used as the platform for the BIM model. In order to implement the method in Revit, Dynamo visual programming is used [37]. Dynamo runs within Revit and works as an Application Programming Interface (API). As a result, Dynamo ensures a seamless integration with Revit. Also, it allows rapid coding within Revit and provides a seamless integration between the Revit model and various simulation tools. As an example, Figure 7 shows the implementation of wall object detection and surface extraction shown in Figure 4.

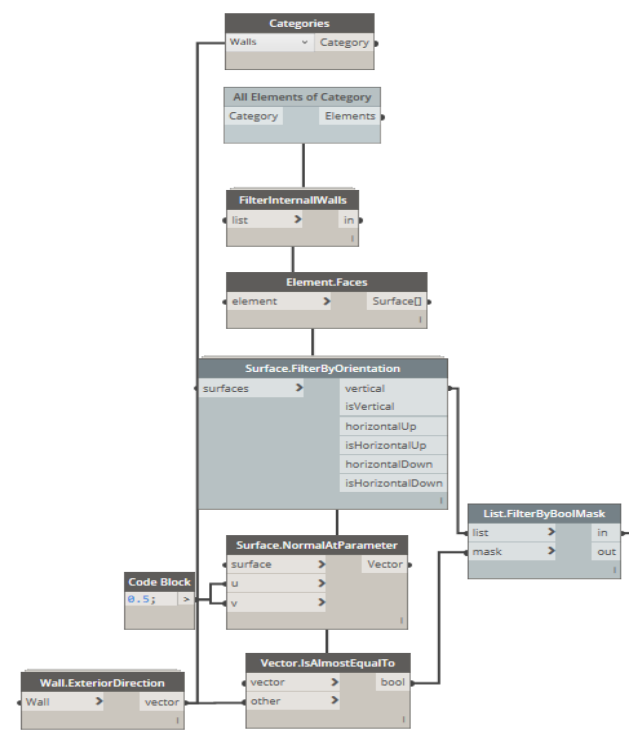

Figure 7. Implementation of wall detection and surface extraction in Dynamo
Similar codes are developed for other parts of the flowchart presented in Figure 2. It is worth noting that some of the nodes, e.g., FilterInternalWalls, are custom nodes that are developed by the authors. To test and validate the developed implementation, a case study is conducted. As shown in Figure 8(a), the case study is performed on Sir George William (SGW) campus of Concordia University in downtown Montreal. The building of John Molson School of Business (JM) is selected for the analysis because of its specific architecture, which includes curtain walls, windows, walls, rooftops, and projected horizontal surfaces at different levels. This complex architecture requires a detailed and surface-specific simulation of the building envelope. The BIM model of JM building is created and imported into Revit. Then, Revit Solar Analyst was used for simulating the solar radiation on the building surfaces For this purpose, it is necessary to set the geographical location of the study area and define the true north of the buildings.

As shown in Figure 8(b), the city blocks around the JM building is extracted from CityGML model provided by the city of Montreal [32]. CityGML file is converted into a .fbx file and later merged with the BIM model as a unique site family in Revit.

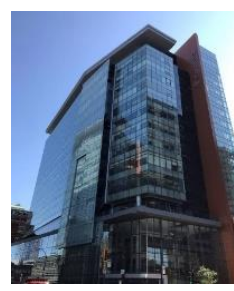

(a)

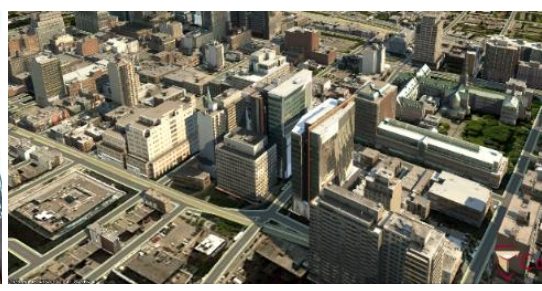

(b)

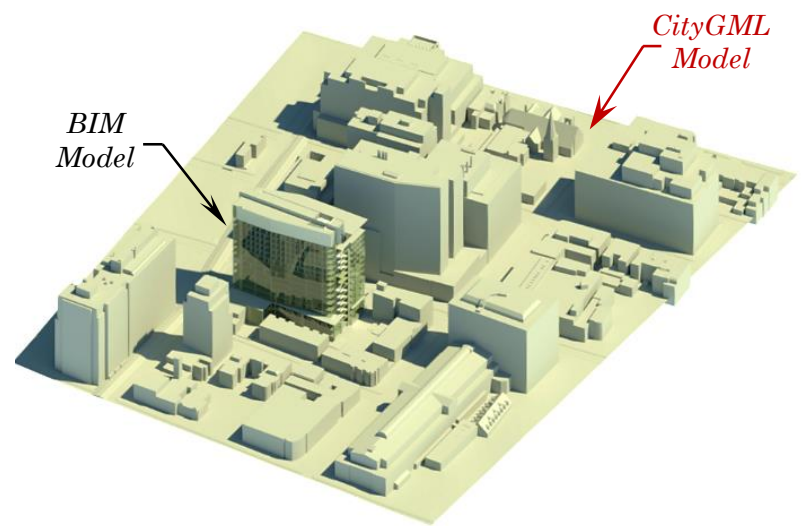

(c)

Figure 8. (a) JM building in downtown Montreal, (b) CityGML model of Concordia SGW campus, and (c) integration of the BIM Model and CityGML in Revit 
Three classes of objects are considered for this case study, namely, roofs, walls, and curtain walls. Figure 9 shows the external surfaces of these elements. It is important for the implementation that elements are modeled using appropriate families and attributes in the BIM model. For the resolution of the simulation analysis, a grid with the spacing of $1 \mathrm{~m}$ is used, as shown in Figure $9(\mathrm{~d}$, e, and $\mathrm{f})$. The weather data is automatically determined based on the site location and the annual solar radiation is calculated for one year.

In the next step, the solar analysis is applied in Dynamo using the predefined node. The radiation value is then calculated for every single point on the grid of the classified surfaces. The corresponding values of the annual solar radiation for each surface type are then stored in a separate Excel sheet. These values are then imported into MATLAB to visualize the simulation results. The results of the simulation for each class of surface are shown in Figure 10. As shown in this figure, in line with the expectations, the higher floors received more radiation. Additionally, the backside of the building which was overshadowed by the surrounding buildings is receiving less radiation than the front side.

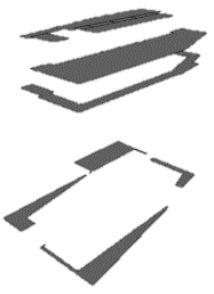

(a)

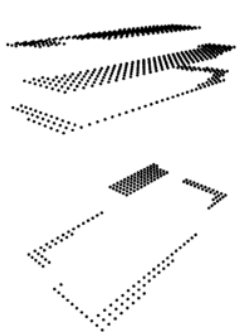

(d)

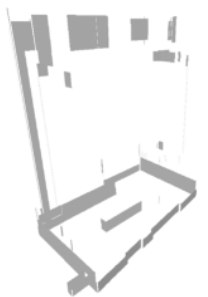

(b)

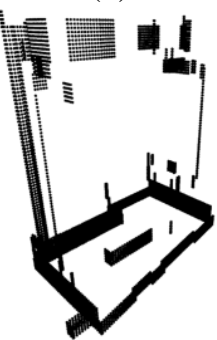

(e)

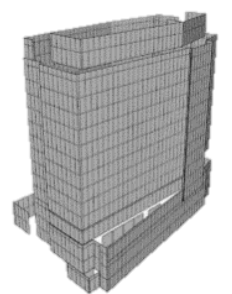

(c)

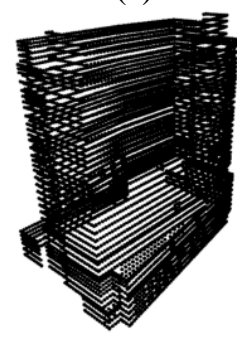

(f)
Figure 9. Extraction of external surfaces of (a) roofs, (b) walls, (c) curtain walls, and resolution of simulation analysis for (d) roofs, (e) walls, and (f) curtain walls

\section{Discussion}

Integration of the simulation results with Matlab to visualize the radiation values will facilitate the next step of the project to optimize the PV panel installation. Although this paper focused on a single building to perform the radiation analysis, analyzing multiple buildings can be done by combining several BIM models. In order to do that it is necessary to index each building based on its address to allow identification of buildingspecific surfaces.

\section{Conclusions and Future work}

In this paper, a BIM-based method is developed for a detailed simulation of a building envelope using its surface properties. The BIM model provided the basis for creating different categories of surfaces associated with different types of building objects such as exterior walls, roofs, curtain walls, and windows.

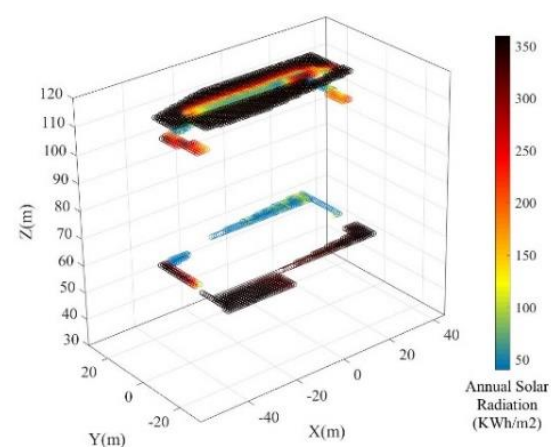

(a)

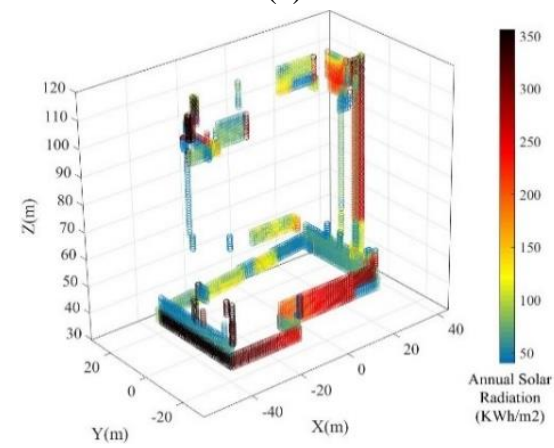

(b)

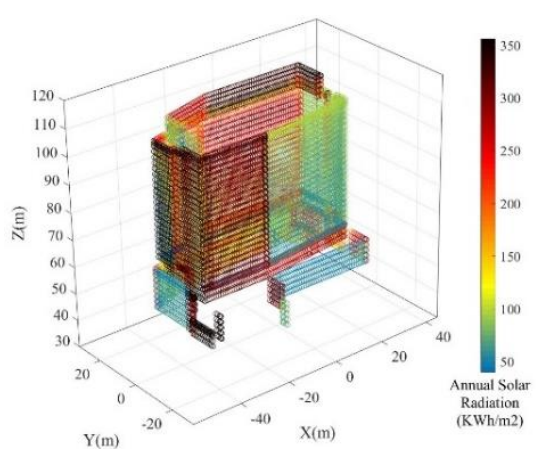

(c)

Figure 10. Visualized results of the solar radiation simulation for (a) roofs, (b) walls, and (c) curtain walls 
A prototype is developed using Revit and Dynamo visual programming platform, and a case study is presented for a building in Montreal, Canada, to demonstrate the feasibility of the proposed method.

In the light of the result of the case study, it can be concluded that the proposed method is promising in terms of providing the input for a comprehensive planning of the solar panel layout. Future work will aim to optimize the installation of PV modules on building surfaces considering maximum energy generation and minimum life cycle cost of the modules.

\section{References}

[1] Charabi, Y., Rhouma, M. B. H. and Gastli, A., GISbased estimation of roof-PV capacity \& energy production for the Seeb region in Oman. In the Proceedings of Energy Conference and Exhibition (EnergyCon), IEEE International. Pages 41-44, 2010.

[2] International Energy Agency, Renewables

[3] Hestnes, A. G. Building integration of solar energy systems. Solar Energy, 67(4):181-187, 1999.

[4] Norton, B., Eames, P. C., Mallick, T. K., Huang, M. J., McCormack, S. J., Mondol, J. D., \& Yohanis, Y. G. Enhancing the performance of building integrated photovoltaics. Solar Energy, 85(8):16291664, 2011.

[5] Kucuksari, S., Khaleghi, A. M., Hamidi, M., Zhang, Y., Szidarovszky, F., Bayraksan, G., and Son, Y. J. An Integrated GIS, optimization and simulation framework for optimal PV size and location in campus area environments. Applied Energy, 113:1601-1613, 2014

[6] Martín, A. M., Domínguez, J. and Amador, J. Applying LiDAR datasets and GIS based model to evaluate solar potential over roofs: A review. AIMS Energy, 11(2): 326-343, 2015Energy, 65:190-199, 2014.

[7] Bergamasco, L. and Asinari, P. Scalable methodology for the photovoltaic solar energy potential assessment based on available roof surface area: Application to Piedmont Region (Italy). Solar Energy, 85(5):1041-1055, 2011.

[8] Ordóñez, J., Jadraque, E., Alegre, J. and Martínez, G. Analysis of the photovoltaic solar energy capacity of residential rooftops in Andalusia (Spain). Renewable and Sustainable Energy Reviews, 14(7): 2122-2130, 2010.

[9] Yadav, A. K., and Chandel, S. S. Tilt angle optimization to maximize incident solar radiation: A review. Renewable and Sustainable Energy Reviews 23:503-513, 2013.

[10] Nguyen, H. T., Pearce, J. M., Harrap, R., and Barber, G. The application of LiDAR to assessment of rooftop solar photovoltaic deployment potential in a municipal district unit. Sensors, 12(4): 4534-4558, 2012.

[11] Carl, C. Calculating solar photovoltaic potential on residential rooftops in Kailua Kona, Hawaii. (Ph.D. dissertation), University of Southern California, 2014.

[12] Jochem, A., Höfle, B., Rutzinger, M. and Pfeifer, N. Automatic roof plane detection and analysis in airborne lidar point clouds for solar potential assessment. Sensors, 9(7): 5241-5262, 2009.

[13] Freitas, S., Catita, C., Redweik, P. and Brito, M. C. Modelling solar potential in the urban environment: State-of-the-art review. Renewable and Sustainable Energy Reviews, 41:915-931, 2015.

[14] Šúri, M. and Hofierka, J. A new GIS-based solar radiation model and its application to photovoltaic assessments. Transactions in GIS, 8(2): 175-190, 2004.

[15] Jakubiec, J. A., and Reinhart, C. F. A method for predicting city-wide electricity gains from photovoltaic panels based on LiDAR and GIS data combined with hourly Daysim simulations. Solar Energy, 93: 127-143, 2013.

[16] Hong, T., Koo, C., Park, J. and Park, H. S. A GIS (geographic information system)-based optimization model for estimating the electricity generation of the rooftop PV (photovoltaic) system.

[17] Ludwig, D., Lanig, S., and Klärle, M. Sun-area towards location-based analysis for solar panels by high resolution remote sensors (LiDAR). In Proceedings of International Cartograhy Conference, Santiago de Chile, 2009.

[18] Catita, C., Redweik, P., Pereira, J., and Brito, M. C. Extending solar potential analysis in buildings to vertical facades. Computers \& Geosciences, 66:112,2014

[19] Liang, J., Gong, J., Li, W., and Ibrahim, A. N. A visualization-oriented 3D method for efficient computation of urban solar radiation based on 3D2D surface mapping. International Journal of Geographical Information Science, 28(4): 780-798, 2014.

[20] Eastman, C. M., Eastman, C., Teicholz, P., and Sacks, R. BIM handbook: A guide to building information modeling for owners, managers, designers, engineers and contractors. John Wiley \& Sons, 2011.

[21] Wang, J., Li, J., and Chen, X. Parametric design based on building information modeling for sustainable buildings. In Proceeding of International Conference on Challenges in Environmental Science and Computer Engineering (CESCE), IEEE, Pages 236-239, 2010

[22] Gourlis, G., and Kovacic, I. Building Information 
Modelling for analysis of energy efficient industrial buildings-A case study. Renewable and Sustainable Energy Reviews, 68: 953-963, 2017.

[23] Abanda, F. H., and Byers, L. An investigation of the impact of building orientation on energy consumption in a domestic building using emerging BIM (Building Information Modelling). Energy, 97: 517-527, 2016.

[24] Habibi, S. The promise of BIM for improving building performance. Energy and Buildings, 153: 525-548, 2017.

[25] eeEmbedded. 2017: http://www.eeembedded.eu/

[26] SolConPro. 2018: http://www.solconpro.de/

[27] Marsh, A. ECOTECT and EnergyPlus. Building Energy Simulation User News, 24(6): 2-3, 2003.

[28] Autodesk. Better Building Performanc. Retrieved from https://insight360.autodesk.com/oneenergy, 2018.

[29] Gao, T., Akinci, B., Ergan, S. and Garrett, J. An approach to combine progressively captured point clouds for BIM update.. Advanced Engineering Informatics, 29(4):1001-1012, 2015.

[30] Roca, D., Armesto, J., Lagüela, S., and DíazVilariño, L. Lidar-equipped UAV for building information modelling. The International Archives of Photogrammetry, Remote Sensing and Spatial Information Sciences, 40(5): 523, 2014.

[31] Bedrick, J. Organizing the development of a building information model. The American Institute of Architects, 9, 2008.

[32] Dore, C., and Murphy, M. Semi-automatic generation of as-built BIM façade geometry from laser and image data. Journal of Information Technology in Construction (ITcon), 19(2): 20-46, 2014.

[33] ClearEdge3D., EdgeWise Building Modeling Tools: http://www.clearedge3d.com/products/edgewisebuilding/

[34] City of Montreal. 2018 : https://donnees.ville.montreal.qc.ca/

[35] City of Rotterdam. 2018: https://www.rotterdam.nl/werken-leren/3d/

[36] Autodesk Revit. 2018: https://www.autodesk.eu/products/revitfamily/overview

[37] Dynamo. 2018: http://dynamobim.org/ 